\title{
Profile of Endoscopic Lesions and Prevalence of $H$. pylori Infection at the Digestive Endoscopy Unit of Panzi General Reference Hospital in Bukavu
}

\author{
Nteranya Musole Adonis ${ }^{1}$, Bwemere Mungwete Josue1,2, Motcheyo Chepig Hyacinthe1, \\ Tchass Chasinga ${ }^{2,3}$, Cimanya Cubaka Fortunat ${ }^{1,2}$, Abedi Zalufa Marlène ${ }^{1,2}$, \\ Bihehe Masemo Dieudonné1,2, Kasereka Kikwaya Jerry', Malamba Lez Didier5, \\ Vangossum Marc 6,7
}

\footnotetext{
${ }^{1}$ Panzi General Reference Hospital, Service of Internal Medicine, Bukavu, Congo (DRC)

${ }^{2}$ Faculty of Medecine, Evangelic University of Africa, Bukavu, Congo (DRC)

${ }^{3}$ Panzi General Reference Hospital, Service of Pathologies, Bukavu, Congo (DRC)

${ }^{4}$ Medical Center of the Community, Service of Radiology, Lubumbashi, Congo (DRC)

${ }^{5}$ University Clinic of Lubumbashi, Service of Internal Medicine, Lubumbashi, Congo (DRC)

${ }^{6}$ UHC Saint Pierre, Service of Gastroenterology, Bruxelles, Belgium

${ }^{7}$ Free University of Brussels, Brussels, Belgium

Email: adonisnteranya@gmail.com
}

How to cite this paper: Adonis, N.M., Josue, B.M., Hyacinthe, M.C., Chasinga, T., Fortunat, C.C., Marlène, A.Z., Dieudonné, B.M., Jerry, K.K., Didier, M.L. and Marc, V. (2021) Profile of Endoscopic Lesions and Prevalence of $H$. pylori Infection at the Digestive Endoscopy Unit of Panzi General Reference Hospital in Bukavu. Open Journal of Gastroenterology, 11, 230-243. https://doi.org/10.4236/ojgas.2021.1111024

Received: September 10, 2021

Accepted: November 13, 2021

Published: November 16, 2021

Copyright (อ 2021 by author(s) and Scientific Research Publishing Inc. This work is licensed under the Creative Commons Attribution International License (CC BY 4.0).

http://creativecommons.org/licenses/by/4.0/

\section{(c) (i) Open Access}

\begin{abstract}
Introduction: Thanks to the opening of the digestive endoscopy unit in the Reference General Hospital of Panzi in Bukavu in the Democratic Republic of the Congo, which inspired our work on the profile of endoscopic lesions observed in a series of 1000 patients correlated with clinical and demographic criteria with the contribution of pathology examinations of the 292 biopsies performed. The aim of our work is to evaluate the prevalence of significant endoscopic lesions as well as that of $H$. pylori infection. Material and Methods: This is a retrospective, descriptive and analytical study, ranging from the $16^{\text {th }}$ of December 2014 to the $16^{\text {th }}$ of June 2016. It covered 1000 patients who benefited from a high digestive endoscopy and 292 of them had a biopsy with pathological examination. The data obtained were recorded and analyzed using the Epi-info software and chi-square test. Results: fifty-five percent of these patients were women. $66 \%$ of the patients were under 50 years of age. Their major symptom was epigastric pain $(89.2 \%)$, the most observed endoscopic lesion was erythematous gastritis (82\%) therefore we have noticed $21.5 \%$ of significant lesions. Gastric cancer was present in $3.9 \%$ of cases and gastric ulcer in $4.2 \%$ of cases. The gastric tumor was correlated with age and
\end{abstract}


sex (P-value at 0.000 and 0.013$)$. The gastroduodenal ulcer was linked to age, NSAID and tobacco use (P-value at 0.0007, 0.001, 0.007). Esophageal mycosis was correlated with HIV status (P-value at 0.000). Helicobacter pylori gastritis was the most frequent $(61.30 \%)$ and Helicobacter pylori were present in $63 \%$ of gastric biopsies. Conclusion: Upper digestive endoscopy is a major tool for the diagnosis of upper gastrointestinal disorders and should always be followed by a biopsy if there is a suspicious lesion for pathologic confirmation and adequate management.

\section{Keywords}

High Digestive Endoscopy, Lesion, H. pylori

\section{Introduction}

Access to health care is limited in the South-Kivu region because of insufficient medical supply and the precariousness of the population [1]. Therefore, some paraclinical examinations remain essential in the diagnostic process and care in our environment like upper digestive endoscopy.

The advent of endoscopy, more particularly gastroscopy, has revolutionized the diagnosis of oeso-gastroduodenal diseases [2] [3]. In France, for example, B. Moulinier and Ph. Grenier Boley report that, in $85 \%$ of cases of upper gastrointestinal bleeding, emergency endoscopy could provide valuable information concerning either the diagnosis by direct observation of the lesion or the location of the bleeding which can guide the surgical procedure [4]. In Japan, Shin et al. reported having detected 14,436 neoplastic lesions by endoscopy over a period of 13 years [5].

In Africa even if digestive endoscopy remains little established, it remains of great diagnostic contribution for pathologies of the digestive tract. In Benin for example, out of 930 esogastroduodenal endoscopies performed in 18 months at the National Hospital and University Center (CNHU) of Cotonou 1992, 91\% of these revealed lesions [6].

In Lomé, Lawson-Ananissoh et al. in 2014 performed upper digestive endoscopy in 2795 patients and observed 3485 lesions distributed as follows: inflammatory pathology predominated (56.3\%), ulcerative pathology (13.89\%), tumor pathology (2.01\%) [7].

It should be noted that upper gastrointestinal fibroscopy is often coupled with biopsy of the gastric and/or duodenal mucosa in order not only to make an anatomopathological diagnosis of the lesions observed on endoscopy but also to look for the presence of Helicobacter pylori.

In the Democratic Republic of Congo and particularly in Bukavu, there are very few studies on endoscopic lesions observed in the environment and even less on the prevalence of Helicobacter pylori infection. This is why it seemed opportune in this work to draw up a succinct picture of endoscopic lesions as 
observed in our daily practice and as well as the contribution of pathological anatomy on digestive pathology and the role of $H$. pylori in digestive affections. Therefore, this work pursues the following objectives:

- Determine the frequency of different endoscopic lesions in our environment.

- Give the influence of certain demographic parameters on the occurrence of these lesions.

- To determine the etiology of gastric and duodenal lesions at histology.

\section{Material and Methods}

\subsection{Study Framework}

We carried out this study in the digestive endoscopy service and the pathological anatomy service of the Panzi General Reference Hospital, a University Hospital managed by the medical works of the 8th Pentecostal Community in Central Africa (8th CEPAC), part of the Churches of Christ in the Congo. It is located in Ibanda Township, Panzi district, on Mushununu Avenue 8 kilometers from the city center, south side, and about 700 meters from the Bukavu-Uvira national road, in the city of Bukavu in the Democratic Republic of the Congo.

\subsection{Materials}

The study population consisted of all the patients coming for an upper gastrointestinal endoscopy during the entire study period from the $16^{\text {th }}$ of December 2014 to the $16^{\text {th }}$ of June 2016 . We had a number of 1000 patients whose age varies from 1 year to 95 years with a median of 42 years of which 292 biopsies were available.

\subsection{Methods}

\subsubsection{Type and Period of Study}

This is a retrospective, descriptive and single-center analytical study involving 1000 patients who underwent upper gastrointestinal endoscopy with a FUII video endoscope $E G-200$ and a 2500 series processor. Of these patients, 292 received a biopsy for pathological analysis (affordability).

\subsubsection{Inclusion Criteria}

- All patients who underwent upper gastrointestinal endoscopy during the study period.

- All patients who have had the necessary means for accessibility to the pathological anatomy examination.

- We defined as significant lesions: esophageal varices, benign esophageal strictures, esophageal tumor, gastric tumor and gastro-duodenal ulcer.

\subsubsection{Exclusion Criteria}

- All patients with only a colonoscopy and a rectoscopy.

- All patients who have had a control upper gastrointestinal endoscopy.

- All patients on treatment of proton pump inhibitors. 


\subsubsection{Parameters Analyzed}

- Demographic criteria: age ( \pm 50 years), sex, consumption of tobacco, nonsteroidal anti-inflammatory drugs (NSAIDs), and HIV status.

- Clinical criteria: epigastralgia, heartburn, vomiting, gastrointestinal bleeding, weight loss, dysphagia.

- Endoscopic lesions: esophageal varices, benign esophageal strictures, peptic ulcers, esogastric cancers.

- Anatomopathological criteria: the staining technique was carried out as follows:

1) The gastric biopsy sample is stored in $10 \%$ formalin.

2) The sample will be dehydrated with ethanol for one hour and then lightened with $x y l o l$ for 30 minutes and finally an impregnation with liquid paraffin for one hour.

3) Embed the tissues in a paraffin block which will be cut with a microtome.

4) Make a microtome cut.

5) Do the staining itself with HEMATOXYLINE EOSIN to establish the pathological diagnosis:

- Harris hematoxylin bath for 2 minutes.

- rinse in running water quickly.

- acid alcohol bath for $1 \mathrm{mn}$ (bleach).

- lithium carbonate bath for $1 \mathrm{mn}$.

- rinse with running water quickly.

- $1 \%$ eosin bath for 2 minutes.

6) To color with GIEMSA for the research of Helicobacter pylori:

- The Giemsa histological kit is used or else the Giemsa used in parasitology is diluted to $1 / 10$ th.

- Cover the slide containing gastric tissue for five minutes then wash and dry.

- The reading will be done under a microscope at magnifications between $40 \times$ and $100 \times$.

NB: All these steps can be carried out in part automatically using a PLC.

\subsection{Data Analysis}

All the data collected were entered and analyzed using the Epi-software Info version 7.1.3.3 and Excel software version 2013. The Chi-Square test was used to compare our results which were significant for a probability $\mathrm{P}<0.05$. Our results will be presented in raw form, either in the form of tables or figures.

\section{Results}

The study population consisted of all the patients coming for an upper gastrointestinal endoscopy during the entire study period. We had a number of $1000 \mathrm{pa}-$ tients among which 450 men and 550 women whose age varies from 1 year to 95 years with a median of 42 years of which 292 biopsies were available. Then we are going to describe here endoscopic lesions of 1000 patients but the pathological examination of samples concerns only 292 biopsies available. 


\subsection{Sociodemographic Criteria}

\subsubsection{Sex}

The following figure (Figure 1) shows the distribution of patients by sex.

This graph shows that more women came to the consultation (55\%) compared to men $(45 \%)$.

\subsubsection{Age}

Figure 2 below shows the distribution of patients by age.

This graph shows us the very high percentage of people under 50 who came to the consultation (66\%) compared to those over 50 (34\%).

\subsection{Clinical Criteria}

\subsubsection{Symptoms Involved}

Figure 3 below shows the distribution of patients according to symptoms.

From this graph, we can see that the dominant symptom in consultation was epigastralgia (89.2\%), followed by vomiting (6.8\%), Gastro-intestinal bleeding (5.8\%), Heartburn (5.5\%), Loss of weight (4.9\%) and at last dysphagia (2.2\%). We have to mention that we could notice some patients showing many of these symptoms at the same time.

\subsubsection{Endoscopic Lesions Observed}

Figure 4 below shows the distribution of patients according to the endoscopic lesions observed.

Figure 4 shows that inflammatory pathologies were the lesions most frequently encountered on endoscopy among which gastritis (82\%), esophagitis
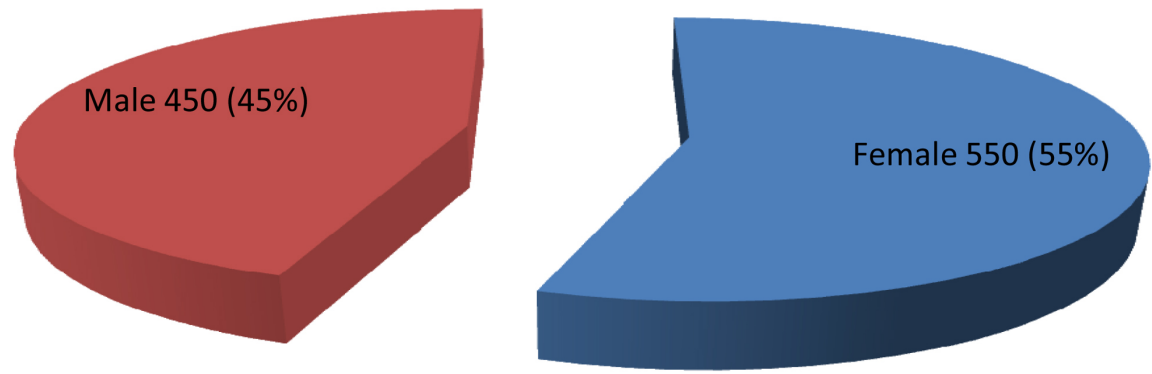

Figure 1. Distribution of patients by sex.

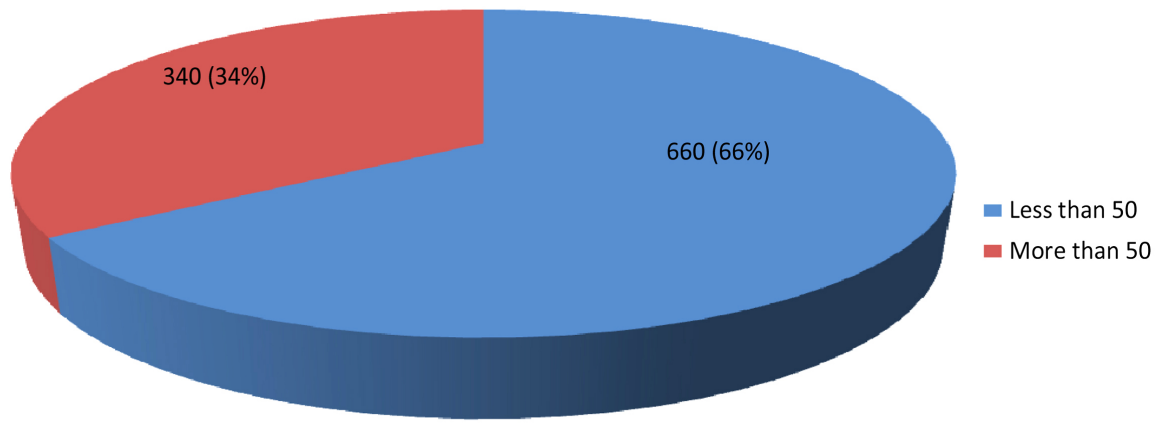

Figure 2. Distribution of patients by age group. 


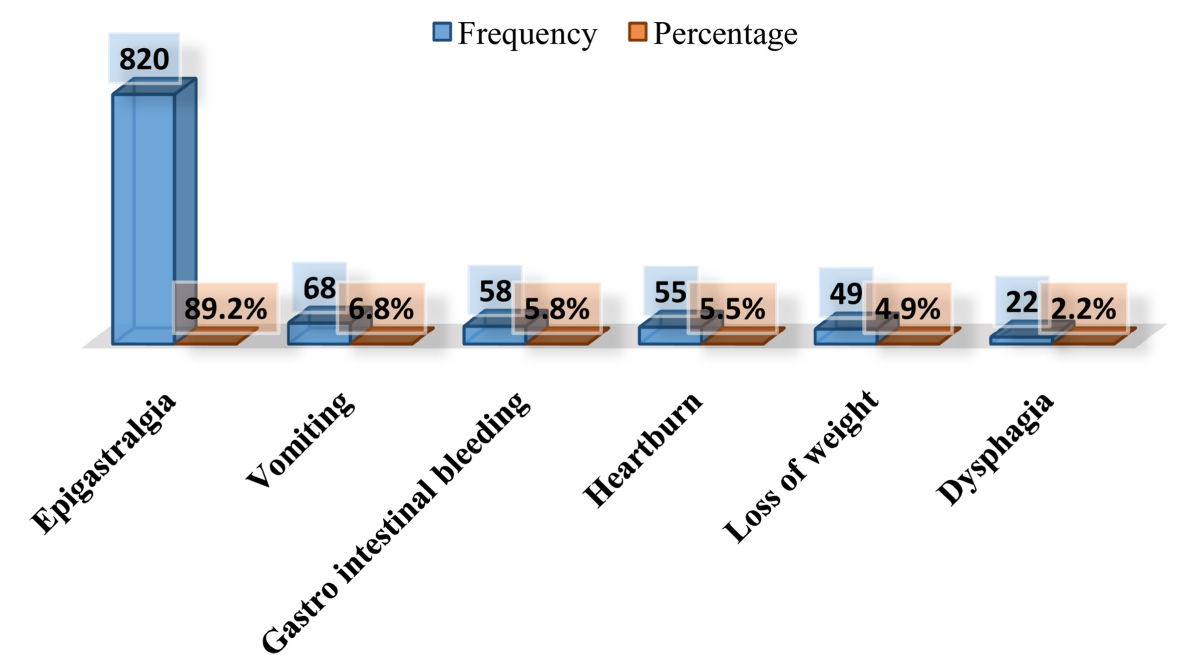

Figure 3. Distribution of patients according to symptoms.

Endoscopic lesions

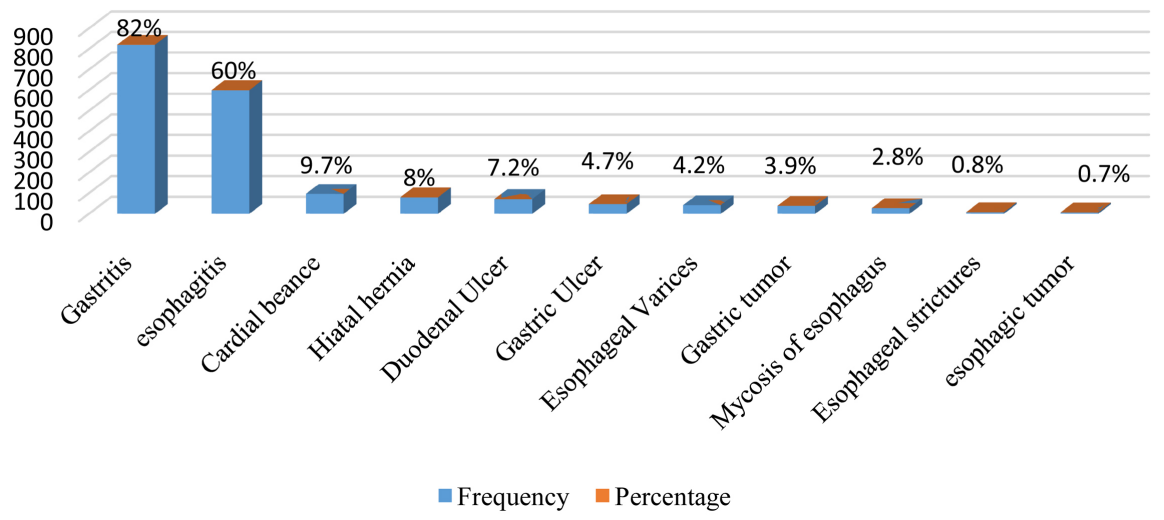

Figure 4. Distribution of patients according to the endoscopic lesions observed.

(60\%). Ulcerative pathologies come at the second time, gastric ulcers (4.7\%), Duodenal ulcers (7.2\%) and tumors come at the third, gastric tumor $(3.9 \%)$, Esophageal tumor $(0.7 \%)$. We then noticed $21.5 \%$ of significant lesions (esophageal varices, benign esophageal strictures, esophageal tumor, gastric tumor and gastro-duodenal ulcer).

\subsection{Correlation with Demographic and Clinical Data}

Table 1 below shows the correlation between gastric tumor and age.

We note that the gastric tumor was correlated with age over 50 years with a P-value $<0.001$ that is $8.4 \%$ of people over 50 with gastric tumor and $1.3 \%$ of people under the age of 50 with gastric tumor.

It emerges from this table that the gastric tumor was significantly associated with the male sex with a P-value of 0.013 . That is $5.6 \%$ men with gastric tumor and $2.5 \%$ women with gastric tumor (Table 2).

From this table, it emerges that the tumor of the esophagus was correlated with the male sex with a P-value equal to 0.029 . That is $1.3 \%$ of men with esophagic 
Table 1. Gastric tumor with age.

\begin{tabular}{cccc}
\hline \multicolumn{4}{c}{ Gastric tumor } \\
\hline Age & No n $(\%)$ & Yes n $(\%)$ & P-value \\
\hline$<50$ years & $626(98.7 \%)$ & $8(1.3 \%)$ & \\
$>50$ years & $336(91.6 \%)$ & $31(8.4 \%)$ & $<0.001^{\star \star} \mathrm{S}$ \\
Total & $962(96.1 \%)$ & $39(3.9 \%)$ & \\
\hline
\end{tabular}

S: Significant.

Table 2. Gastric tumor with sex.

\begin{tabular}{cccc}
\hline \multicolumn{4}{c}{ Gastric tumor } \\
\hline Sex & No n (\%) & Yes n (\%) & P-value \\
\hline Female & $538(97.5 \%)$ & $14(2.5 \%)$ & $0.013^{\star *} \mathrm{~S}$ \\
Male & $422(94.4 \%)$ & $25(5.6 \%)$ & \\
Total & $962(96.1 \%)$ & $39(3.9 \%)$ &
\end{tabular}

S: Significant.

tumor and $0.2 \%$ women with esophagic tumor (Table 3 ).

We note that peptic ulcer disease was correlated with age greater than 50 years with a P-value equal to 0.007 . What means $5.4 \%$ of people over 50 having gastro-duodenal ulcer against $4.2 \%$ of people under the age of 50 having that same disease (Table 4).

From this table it clearly emerges that peptic ulcer was associated with $N S A$ IDs consumption (P-value of 0.001 ) and smoking (P-value of 0.007 ). 14.3\% of ulcers were noticed among patients taking NSAIDs and $25 \%$ of ulcers were noticed among patients taking Tobacco. In some patients, we noticed both NSAIDs and Tobacco consumption (Table 5).

This table (Table 6) shows us that esophageal varices are significantly associated with the male sex with a P-value of 0.049 . This means $5.6 \%$ men with esophageal varices and $3.1 \%$ women.

We can see from this table (Table 7) that mycosis of the esophagus was correlated with HIV status with a P-value $<0.001$. That is $63.3 \%$ of mycosis was observed in HIV patients and $1 \%$ of mycosis only in HIV-negative people.

\subsection{Anatomo-Pathological Criteria}

\subsubsection{Distribution of Cases According to Anatomo-Pathological Diagnosis}

It emerges from this figure (Figure 5) that Helicobacter pylori gastritis was the most described lesion either $61.30 \%$ compared to chronic non-specific gastritis $28.77 \%$. Gastric adenocarcinoma was observed in $3.42 \%$ of cases.

\subsubsection{Breakdown of Cases by Presence or Not of Helicobacter pylori}

This figure (Figure 6) shows a high prevalence of Helicobacter pylori 63\% on the biopsy samples taken. 
Table 3. Esophagic tumor with sex.

\begin{tabular}{cccc}
\hline \multicolumn{4}{c}{ Esophagic tumor } \\
\hline Sex & No n (\%) & Yes n (\%) & P-value \\
\hline Female & $551(99.8 \%)$ & $1(0.2 \%)$ & $0.029^{\star \star} \mathrm{S}$ \\
Male & $441(98.7 \%)$ & $6(1.3 \%)$ & \\
Total & $992(99.3 \%)$ & $7(0.7 \%)$ & \\
\hline
\end{tabular}

S: Significant.

Table 4. Gastro-Duodenal ulcer with age.

\begin{tabular}{cccc}
\hline \multicolumn{4}{c}{ Gastro-duodenal Ulcer } \\
\hline Sex & No n $(\%)$ & Yes n $(\%)$ & P-value \\
\hline$<50$ years & $529(95.8 \%)$ & $23(4.2 \%)$ & \\
$>50$ years & $423(94.6 \%)$ & $24(5.4 \%)$ & $0.007^{\star *} \mathrm{~S}$ \\
Total & $952(95.3 \%)$ & $47(4.7 \%)$ & \\
\hline
\end{tabular}

S: Significant.

Table 5. Gastro-Duodenal ulcer with age.

\begin{tabular}{ccccc}
\hline \multirow{2}{*}{ Variables } & & \multicolumn{2}{c}{ Gastro-duodenal Ulcer } & \multirow{2}{*}{ P-value } \\
\cline { 3 - 3 } & & \multicolumn{2}{c}{ No n (\%) Yes n (\%) } & \\
\hline $\begin{array}{c}\text { NSAIDs } \\
\text { consumption }\end{array}$ & No & $900(95.8 \%)$ & $39(4.2 \%)$ & $0.001^{\star *} \mathrm{~S}$ \\
& Yes & $48(85.7 \%)$ & $8(14.3 \%)$ & \\
& Total & $948(95.3 \%)$ & $47(4.7 \%)$ & \\
\hline Tobacco & No & $945(96.1 \%)$ & $45(3.9 \%)$ & $0.007^{\star *} \mathrm{~S}$ \\
consumption & Yes & $6(75.0 \%)$ & $2(25.0 \%)$ & \\
& Total & $951(95.3 \%)$ & $47(4.7 \%)$ & \\
\hline
\end{tabular}

Table 6. esophageal varices with sex.

\begin{tabular}{cccc}
\hline \multicolumn{4}{c}{ Esophageal varices } \\
\hline Sex & No n (\%) & Yes n (\%) & P-value \\
\hline Female & $535(96.9 \%)$ & $17(3.1 \%)$ & $0.049^{\star *}$ \\
Male & $422(94.6 \%)$ & $25(5.6 \%)$ & \\
Total & $957(95.8 \%)$ & $42(4.2 \%)$ & \\
\hline
\end{tabular}

Table 7. Mycosis of esophagus with HIV status.

\begin{tabular}{cccc}
\hline \multicolumn{4}{c}{ Mycosis of Esophagus } \\
\hline HIV status & No n (\%) & Yes n (\%) & P-value \\
\hline Negative & $959(99.0 \%)$ & $10(1.0 \%)$ & \\
Positive & $11(26.7 \%)$ & $19(63.3 \%)$ & $<0.001^{\star *} \mathrm{~S}$ \\
Total & $970(92.8 \%)$ & $29(7.2 \%)$ & \\
\hline
\end{tabular}


ANATOMOPATHOLOG ICAL DIAGNOSIS

E frequency = Percentage

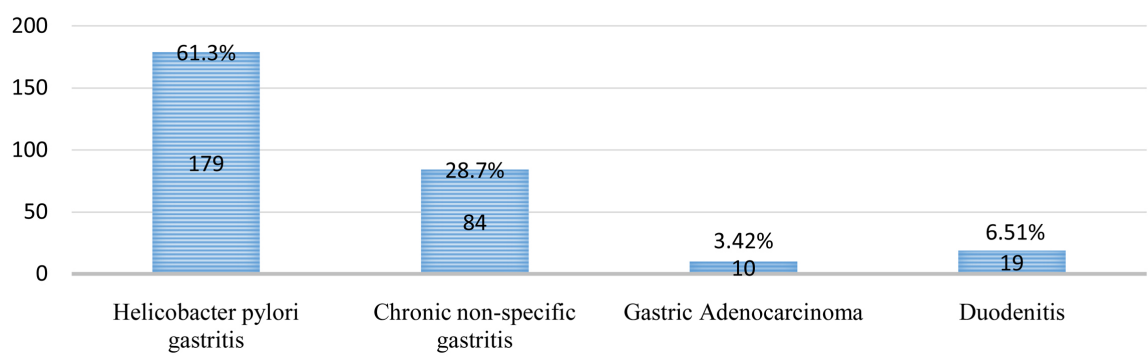

Figure 5. Distribution of cases according to pathological diagnosis.

Helicobacter pylori testing in anatomopathology

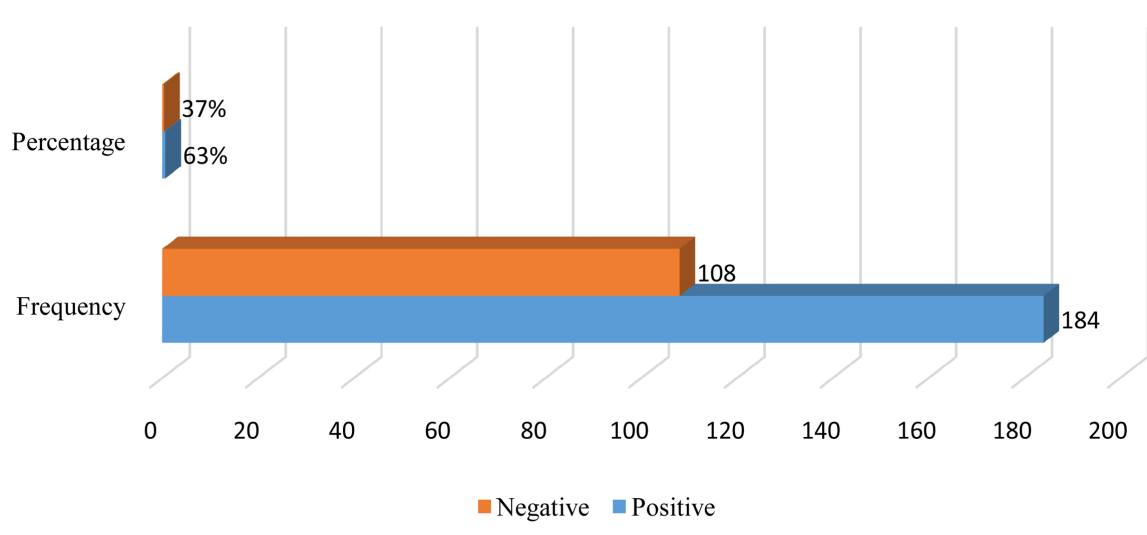

Figure 6. Distribution of cases according to the presence or absence of Helicobacter pylori.

\section{Discussion}

\subsection{Limitations of the Study}

This work was based only on the sample of patients referred to us for digestive endoscopy which represents only a few parts of the population suffering from digestive disorders because not everyone can pay for the exam. We would like to have an idea of the role of Helicobacter pylori in the occurrence of digestive lesions but we have been limited by the sample (292) of biopsies analyzed in pathology which might have underestimated the real prevalence of $H$. Pylori in our area. We then hope that in the future some other studies with big sample sizes will be necessary in order to fix the problem correctly. This work was a single-center analytical study, though our results match with the majority of studies as we can see further in the discussion, there is a need to have the reality of all the hospitals that perform digestive endoscopy in our area for more conclusive results.

\subsection{Sociodemographic Criteria}

\subsubsection{The Sex}

In our study, we noticed that more women (55\%) came for consultation compared to men (45\%). Our results are different from those of Ibara et al. at Braz- 
zaville who received $50.73 \%$ of men and $49.26 \%$ of women in consultation [8]. However, our results are similar to those of Lawson-Ananissoh et al. in Togo in 2014 which received $57.49 \%$ of women in consultation compared to $42.51 \%$ [7].

This result could be explained by the fact that women are more inclined to come for consultation at the first sign.

\subsubsection{Age}

We noticed a very high percentage of people under 50 in consultation (66\%) compared to those over 50 (34\%). Our results are superimposable on those of Lawson-Ananissoh et al. in Togo where the most represented age group was between 25 years and 44 years old [7].

This could be explained by the structure of the population of developing countries with a high proportion of young subjects in the population.

\subsection{Clinical Criteria}

\subsubsection{The Symptoms Involved}

In our series, we found that the dominant symptom in the consultation was epigastralgia (89.2\%). Our results join those of Ndjitoyap Ndam et al. in Cameroon in whom epigastralgia (52.77\%) represented half of the symptoms [9]; as well as those of Hountondjia et al. in Benin who noted 43.55\% of epigastralgia [6]. The results of Lawson-Ananissoh et al. in Togo go in the same direction with a frequency of epigastralgia at $60.68 \%$ [7].

\subsubsection{Endoscopic Lesions Observed}

Our series shows that inflammatory pathologies were the leading lesions encountered on endoscopy. Ulcerative pathologies came second with gastric ulcers at $4.7 \%$ and duodenal ulcers at $7.2 \%$. Finally, cancerous pathologies are in third place with gastric cancers at $3.9 \%$ and esophageal cancer at $0.7 \%$.

Our results corroborate those of Ndjitoyap Ndam et al. who found a predominance of inflammatory pathologies at $54.65 \%$, followed by ulcer pathologies at $31.65 \%$ and finally tumor pathologies at $2.97 \%$ [9]. The results of Lawson-Ananissoh et al. go in the same direction with a predominance of inflammatory pathology at $56.3 \%$; followed by ulcer pathology at $13.89 \%$ and finally tumor pathology at $2.01 \%$.

This high predominance of inflammatory pathology in tropical environments could be related to the Helicobacter pylori infection which is very widespread in developing countries, but also with the multiple aggressive factors for the gastric mucosa, in particular self-medication with products gastro-toxic, and bad eating habits.

\subsection{Correlation of Demographic and Clinical Data}

\subsubsection{Gastric Tumor with Age}

We notice that the gastric tumor is significantly associated with age greater than 50 years with a $\mathrm{P}$-value equal to 0.000 , this corroborates the results of Ibar et al. who found a mean age of onset of the gastric tumor at 51.1 years [8]; as well as 
those of Hountondjia et al. in whom the majority of patients with gastric tumor were aged between 55 and 69 years [6]. Diarra et al. in Mali in 2014 joined us with an average age of onset of gastric tumor at 56.51 years [10]. Bougougla et al. in Togo in 2014 are not left with an average age of onset of gastric tumor at 58.8 years [11], as well as Mellouki et al. in Morocco in 2014 who found an average age of onset at 58 years [12].

All this could be explained by the fact of the infection with Helicobacter pylori which was recognized as a type I carcinogen by the international agency for research on cancer in 1994 [13] and involved in around 80\% of stomach cancers [14] after almost 30 years of evolution of the infection [15].

\subsubsection{Gastric Tumor with Sex}

Our analysis showed that gastric tumor was significantly correlated with male sex with a P-value of 0.013 . Our results join those of Mellouki et al. in Morocco in 2014 who found a clear male predominance with a P-value of less than 0.05

[12], as well as those of Diarra et al. who found a sex ratio of 1.6 in favor of men [10]. The male predominance was also found by Bougougla et al. who found a sex ratio of 2.5 in favor of men [11].

This distribution would be due to more frequent consumption of tobacco in males in our environment and constitutes a cofactor of gastric carcinogenesis.

\subsubsection{Esophagus Tumor with Sex}

Our series highlights the fact that the esophageal tumor was significantly correlated with the male sex with a P-value equal to 0.029 . This result is superimposable on that of Hountondjia et al. who found that the tumor of the esophagus was the prerogative of humans (21 out of 25 cases) [6].

All of this could be explained by chronic alcoholism and smoking, which are common in humans and which are risk factors for cancer of the esophagus.

\subsubsection{Gastroduodenal Ulcer with Age}

We note in our series that peptic ulcer was significantly correlated with age greater than 50 years with a $\mathrm{P}$-value equal to 0.007 . But our results do not match those of Diarra et al. in Bamako in 2009 who found that the most represented age group was between 30 years and 49 years old with a rate of $47.8 \%$ [16]. Ibar et al. noted an average age of 41.33 years [17].

This discrepancy can be explained by the fact that the peptic ulcer is the result of the imbalance between the stressors and the protective factors of the stomach; the occurrence of these factors is not dependent on age.

\subsubsection{Gastroduodenal Ulcer with Tobacco and NSAIDs}

It was clear from our study that peptic ulcer disease was significantly correlated with taking NSAIDs (P-value of 0.001) and smoking (P-value of 0.007).

Our results agree with those of Ibar et al., who found smoking in $16 \%$ of patients and taking NSAIDs in $46 \%$ of ulcer patients, thus being major sources of peptic ulcer disease [17]. 
All this could be explained by the fact that NSAIDs are drugs that are heavily consumed in self-medication. These drugs produce a weakening of the mucous membrane defenses which can promote, reactivate or complicate the ulcer.

\subsubsection{Esophagian Varices with Sex}

Our series showed that esophageal varices were significantly correlated with male sex with a P-value of 0.049 . Our result corroborates that of Lawson-Ananissoh et al. in Togo who found an association of male esophageal varices with a P-value of 0.000 [7].

This result could be explained by the fact that esophageal varices are endoscopic signs of portal hypertension, the main cause of which is cirrhosis, which affects both men and women [18].

\subsubsection{Mycosis of Esophagus with HIV Status}

We note from our study that mycosis of the esophagus was significantly correlated with HIV status with a P-value of 0.000 , which is $63 \%$ of seropositive patients.

Our results are close to those of Ngatcha et al. in Rabat in 2014 who found, out of a total of 68 seropositive, 19 cases of mycotic esophagitis, which is $37 \%$ of cases [19].

All this is explained by the fact that Candida albicans are the main cause of opportunistic infections of the esophagus in HIV. Patients often develop dysphagia and odynophagia [20].

\subsection{Distribution of Cases According to the Presence or Not of Helicobacter pylori}

In our series, the presence of Helicobacter pylori was $63 \%$ of cases. Our results are superimposable on those of Essadik et al. in 2013 in Casablanca with a prevalence of H. pylori of 69.2\% [21]. Ankouane et al. in 2013 in Yaoundé found a prevalence of $72.5 \%$ [22]. Ilboudo et al. in Ouagadougou found an even higher prevalence, $81.3 \%$ [23].

This high prevalence of $H$. Pylori in these developing countries is explained by the precarious sanitary conditions, great promiscuity, ignorance of the infection and often limited access to treatment [24] [25] [26] [27].

\section{Conclusions}

The objectives of our study were not only to determine the frequency of different endoscopic lesions in our environment and to give the influence of certain demographic parameters on the occurrence of certain lesions but also to determine the relative prevalence of Helicobacter pylori infection in our sample and its relation to certain endoscopic lesions.

Our study which was retrospective, descriptive and analytical going from the $16^{\text {th }}$ of December 2014 to $16^{\text {th }}$ of June 2016 led to the following conclusions:

- The major symptom that prompted patients to come to the hospital was 
$89.2 \%$ epigastralgia.

- During upper gastrointestinal endoscopy, we observed $21.5 \%$ of significant lesions.

- Gastric cancer was quite common in our environment (3.9\%).

- The gastric tumor was significantly correlated with age and sex and was the correlation of esophageal tumor to sex.

- Peptic ulcer disease was significantly correlated with age, tobacco use and NSAIDs.

- Mycosis of the esophagus was significantly correlated with HIV status.

On histology, the presence of Helicobacter pylori was effective in $63 \%$ of cases.

\section{Conflicts of Interest}

The authors declare no conflicts of interest regarding the publication of this paper.

\section{References}

[1] Van Gossum, M., Adonis, N.M., Steve, N., et al. (2017) Epidemiological Profile of Lesions Observed in the Service of Gastroenterology at the Panzi General Reference Hospital-Bukavu-South-Kivu, DRC. Congress Palace, Paris, $181 \mathrm{p}$.

https://snfge.org/thematiques/imagerie?page $=7$

[2] Heyries, L., Durieux, O., Mirabel T., et al. (2017) Imaging of Non-Tumor Pathology of the Stomach and Duodenum.

https://em-consulte.com/article/23111/imagerie-de-la-pathologie-non-tumorale-de1-estomac

[3] Barriere, E., Courat, L., Sautereau, D., et al. (2017) Diagnostic and Therapeutic Endoscopy of the Upper Digestive Tract.

https://.em-consulte.com/article/20040/endoscopie-diagnostique-et-thérapeutiquedu-tracus-digestif

[4] Moulinier, B. and Boley, G. (1982) Interest of Emergency Gastroscopy in Upper Digestive Hemorrhages. Acta Endoscopica, 1, 9-12.

[5] Shin, K., Kusaka, H., Yamano, H., et al. (1999) Characteristics of Depressed Early Colorectal Carcinoma (Abstract). Gastrointestinal Endoscopy, 49, AB63.

[6] Hountondjia, K. and Addra, B. (1992) Contribution of Endoscopy to the Diagnosis of Oeso-Gastroduodenal Affections in Tropical Environments. Beninese Experience with 930 Examinations. Black African Medicine, 39, 337-344.

[7] Lawson-Ananissoh, L.M., Bouglouga, O., Bagny, A. and Kaaga, L. (2014) Upper Gastrointestinal Endoscopy in 2795 Patients at the University Campus Hospital of Lomé: Peculiarities According to Sex. The Pan African Medical Journal, 19, Article No. 262. https://doi.org/10.11604/pamj.2014.19.262.4512

[8] Ibara, J.R., Moukassa, B. and Itoua-Ngaporo, A. (1993) Upper Digestive Pathology in Congo. Medecine d Afrique Noire, 40, 97-100.

[9] Ndjitoyap Ndam, E.C., Njoya, O., Mballa, E., et al. (1990) Upper Digestive Endoscopy in Cameroon. Medecine d Afrique Noire, 37, 453-456.

[10] Diarra, M.T., Konate, A., Diarra, A.N., et al. (2014) The Epidemiological and Prognostic Characteristics of Stomach Cancer in Urban Areas in Mali. Mali Medical, 29, 50-54. 
[11] Bougougla, O., Lawson-Ananissoh, L.M., Bagny, A., Kaaga, L. and Amegbor, K. (2015) Stomach Cancer: Epidemiological, Clinical and Histological Aspects at the Lomé Campus CHU (Togo). Tropical Medicine and Health, 25, 65-68.

[12] Mellouki, I., et al. (2014) Epidemiology of Gastric Cancer: Experience of a Moroccan Hospital Center. The Pan African Medical Journal, 17, Article ID: 42.

[13] IARC (1994) Schistosomes, Liver Flukes and Helicobacter pylori. IARC Working Group on the Evaluation of Carcinogenic Risks to Humans, Lyon, 7-14 June 1994, 177-240.

[14] INCA (2014) Risk Factors for Stomach Cancer.

http://www.e-cancer.fr/cancerinfo/Patients-et-proches/Les-cancer/cancer-de-l-esto mac/facteurs-de-risques

[15] Courillon-Mallet, A. (2009) Helicobacter pylori and Gastric Cancer: Eradication to Prevent Cancer? Gastroentérologie Clinique et Biologique, 33, 301-305. https://doi.org/10.1016/j.gcb.2009.02.007

[16] Diarra, M.T., Konate, A., Traore, C., et al. (2009) Gastro-Duodenal Ulcers in Rural Areas in Mali. Mali Medical, 24, 1-3.

[17] Ibara, J.R., Moukassa, B. and Itoua-Ngaporo, A. (1993) Gastric and Duodenal Ulcers in Brazzaville. Medecine d'Afrique Noire, 40, 459-465.

[18] Guy, J. and Peters, M. (2013) Liver Disease in Women: The Influence of Gender on Epidemiology, Natural History and Patient Outcomes. Gastroenterology \& Hepatology, 9, 633-639.

[19] Ngatcha, G., Kabbaj, N., Salihoun, M., et al. (2014) Gastro-Intestinal Lesions in Patients with Acquired Immunodeficiency Syndrome. Hegel, 4, 22-27.

https://doi.org/10.4267/2042/53500

[20] Alyoune, M. and Biadillah, M. (1991) Digestive Disorders of AIDS. Médecine du Maghreb, 25, 5-9.

[21] Essadik, A., Benomar, H., Rafik, I., et al. (2013) Epidemiological and Clinical Aspects of Helicobacter pylori Infection in a Moroccan Study. Hegel, 3, 163-169.

[22] Ankouane, F., Noah, D., Tagni-Sartre, M., et al. (2013) Epidemiology of Helicobacter pylori Infection in Yaoundé: From the Peculiarity to the African Enigma. The Pan African Medical Journal, 16, Article ID: 115.

[23] Ilboudo, D., Sangaré, L., Sanou, J., et al. (1997) Epidemiological and Clinical Aspects of Helicobacter pylori Infection in Tropical Areas. Medecine d Afrique Noire, 44, 24-28.

[24] Nurgalieva, Z., Malaty, H., Graham, D., et al. (2002) Helicobacter pylori Infection in Kazakhstan: Effect of Water Source and Household Hygiene. The American Journal of Tropical Medicine and Hygiene, 67, 201-206. https://doi.org/10.4269/ajtmh.2002.67.201

[25] Vale, F.F. and Vítor, J.M.B. (2010) Transmission Pathway of Helicobacter pylori: Does Food Play a Role in Rural and Urban Areas? International Journal of Food Microbiology, 138, 1-12. https://doi.org/10.1016/j.ijfoodmicro.2010.01.016

[26] Magalhaes Queiroz, D.M. and Luzza, F. (2006) Epidemiology of Helicobacter pylori Infection. Helicobacter, 11, 1-5.

[27] Azevedo, N.F., Guimaraes, N., Figueiredo, C., et al. (2007) A New Model for the Transmission of Helicobacter pylori: Role of Environmental Reservoirs as Gene Pools to Increase Strain Diversity. Critical Reviews in Microbiology, 33, 157-169. https://doi.org/10.1080/10408410701451922 